\title{
Study on the Spatial Structure of Ethnic Settlement in the Upper Reaches of Minjiang River and Its Protection Strategy
}

\author{
Ying Meng \\ School of Urban Planning and Architecture, Southwest University for Nationalities, Chengdu, China
}

\section{Email address:}

396877993@qq.com

\section{To cite this article:}

Ying Meng. Study on the Spatial Structure of Ethnic Settlement in the Upper Reaches of Minjiang River and Its Protection Strategy. Humanities and Social Sciences. Vol. 6, No. 2, 2018, pp. 76-81. doi: 10.11648/j.hss.20180602.15

Received: March 19, 2018; Accepted: April 30, 2018; Published: June 20, 2018

\begin{abstract}
On the characteristics performance of national settlement value, there is not only a single settlement spatial organization characteristic, but also put up the relationship between the organizational structures of settlements. Through the study of field survey and literature on the settlement of ethnic groups upper reaches of Minjiang River, and questionnaire interview of villagers self-organization construction mode, to summarize the construction process between the special geographical environment and the villagers symbiotic relationship upper reaches of Minjiang River, analyze the choice between the Unique social, historical changes of ethnic settlement and Villagers diversified living styles, and point out the logic mechanism of the formation of spatial organization structure in ethnic settlement. At last, putting out that pointing at the spatial structure and characteristics of settlements in different regions should construct corresponding protection strategies and implementation paths in the spatial practice of institutionalized rural settlement.
\end{abstract}

Keywords: Minjiang River, Qiang Settlements, Organizational Characteristics, Protection Strategy

\section{Introduction}

With the promulgation and implementation of urban and rural planning law, the construction of ethnic settlement has many new construction models in its coupling with the external structural elements such as institution and economy, [1] which have a great impact on the spatial representation and characterization space of ethnic settlement. In particular, the ethnic settlements in the upper reaches of the Minjiang River have been rebuilt after the 5.12 disaster. Under the external subject, [2] capital, and power, the ethnic traditional culture emphasizing the form of consumption in the construction process has neglected the organizational structure of social and cultural space in a certain geographical area and Forms of expression, value of social community, cultural community and traditional technical paradigm of national settlement, resulting in some deficiencies in the innovation of spatial characteristics of ethnic settlement, the application of cultural inheritance, the localization of regional manifestations, and regional characteristics.

\section{Problems Facing Village Planning in Ethnic Areas}

\subsection{Insufficient Urban and Rural Planning Practice in Ethnic Areas}

Due to the different types and levels of institutionalized planning practice, different functional roles have been shown in rural planning practice. System planning and regional planning take the overall development sequence and structure of the region as the main content, focusing on the functional arrangements of different settlements and guiding the planning of urban and rural development. System planning and regional planning take the overall development sequence and structure of the region as the main content, focusing on the functional arrangements of different settlements and guiding the planning of urban and rural development. However, the guiding role played by the urban system lacks the connection between the cultural and social relations among the different rural settlements in a certain area, so that the integrity, regionality and characteristic value of the rural settlement area 
are reduced. The social and cultural relations among the spontaneous formation of ethnic settlements in the course of history are neglected or covered up in the construction of spatial practice.

All kinds of construction plans emphasize the implementation and operability, and take the administrative units as the construction units, with the emphasis on the construction of the internal space organizational structure. Usually, the villagers participate in the construction mode, emphasizing the dominant position of the villagers, to maximize the diversity of families to meet the needs of different villagers. The main body of the institutionalized design, implementation and management is different from the endogenous subjects of the villagers in the mode of self-organization construction. Moreover, it is difficult for these subjects to directly experience the needs of the social and cultural life of the ethnic settlement villagers and hardly form the cultural values. [3] Therefore, the spatial representation of rural settlement is subordinated to the cultural and social values of the external subject. It is easy to overlook the impact of the process of cultural value recognition on the spatial organization of settlement, resulting in the loss of the characteristics of the spatial organization structure of ethnic settlement.

\subsection{The Value Needs of Ethnic Settlements in Tourism}

The characteristics of the spatial organization of ethnic settlement are the result of long-term adaptation to the regional environment as well as the cultural creation of the villagers' life. They are rooted in their natural environment and unique social and historical processes, and play an important role in the tourism industry with distinctive features. The characteristics of the spatial organization of the national settlement are not only reflected in the manifestation of the physical structure of the individual settlement, but also the social and cultural organization and structure relationships between the different settlement spaces and the historical cultural information, which can reflect the scale of the characteristic tourism resources value.

The organizational structure of the settlement space not only reflects the consistency of endogenous culture among the villagers' subjects but also shows the social relations and social structure between the settlement spaces constructed in the process of social history. This kind of spatial organization not only has the spatial characteristics of individual settlements but also has the structural characteristics of the relations among them. They represent the main components of tourism content through the cultural and social spatial representation and promote the formation of the overall tourism industry chain.

\subsection{Social Stability and Cultural Inheritance in Minority Areas}

The traditional ethnic settlement spatial organization is the social-spatial relationship in which national culture ties with blood ties and affinal ties. The relationship between neighborhoods is the most important manifestation and the basic social relations outside the family. It reflects the closeness of social relations, forms the social space of settlements, interacts with settlements' cultural belief space and interacts with environment space, and finally achieves settlement spatial organization structure and characteristics. The villagers' recognition of the architectural culture and the space organization has stabilized the social relations and national culture.

Interviews with villagers showed that the villagers in ethnic settlements in the upper reaches of the Minjiang River have strong blood ties and in-laws, the relationship of in-laws in the three generations reached more than $50 \%$, and the relationship of in-laws within the five generations reached more than $80 \%$. In particular, the spatial boundaries of family spaces within Qiang ethnic settlements are vague and their functional layouts are highly similar. (Figure 1) The external appearances of buildings are uniformed, and the interior structures of settlements are interconnected. The integral walls of different family buildings and the integrity of the entire settlement space Strong, become the largest ethnic Qiang ethnic settlement and highlights.

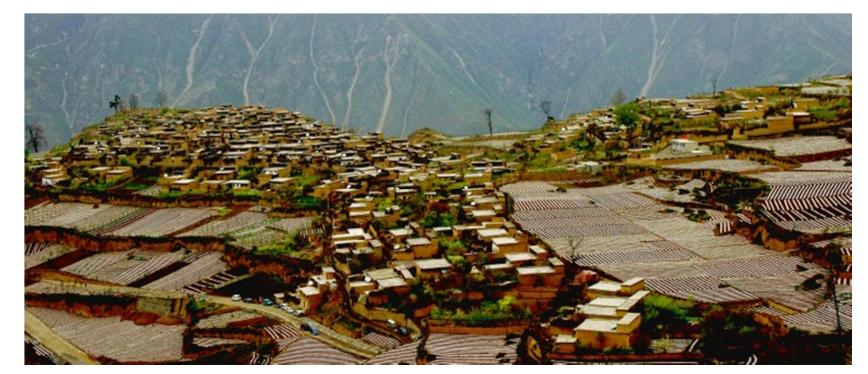

Figure 1. Luobo village in Li County, Sichuan Province.

Source: the photos are provided by the Wenchuan County Bureau of construction

\section{Cognition of the Social Cultural Features of the Ethnic Settlement in the Upper Reaches of Minjiang River}

\subsection{Geographic Environment Has Shaped the Sub-Genre Organization between the Settlement Space (Social and Cultural Attributes Belong to Kinship)}

In the upper reaches of the Minjiang River, due to the vertical distribution of land resources at different altitudes, the settlements relying on farming life are concentrated in the arid valleys and gentle slopes of the lower half of the mountain ranging from 1180 to 3200 meters above sea level. [4] Most of these mountainous [5] settlements are distributed along the waterways and roads in alpine valleys. The gully vertical and horizontal natural environment formed the settlement unit with the mountain as the living unit of space. In the high altitude areas of different mountain units, (Figure 2) there are many smaller settlements distributed around a large-scale settlement. Although there is a certain spatial 
distance between them, there are separate production and living spaces. These natural settlements retain a good ecological environment and primitive traditional culture.

This mother-child style of settlement spatial organization objectively reflects the process of relying on land resources to survive the farming era, villagers limited living space environment, due to population increase access to the maximum living space. The blood relationship and affinity relationship between the settlements ensured the social organization and cultural consistency of mutually beneficial symbiosis. The villagers had strong national identity and cultural identity.

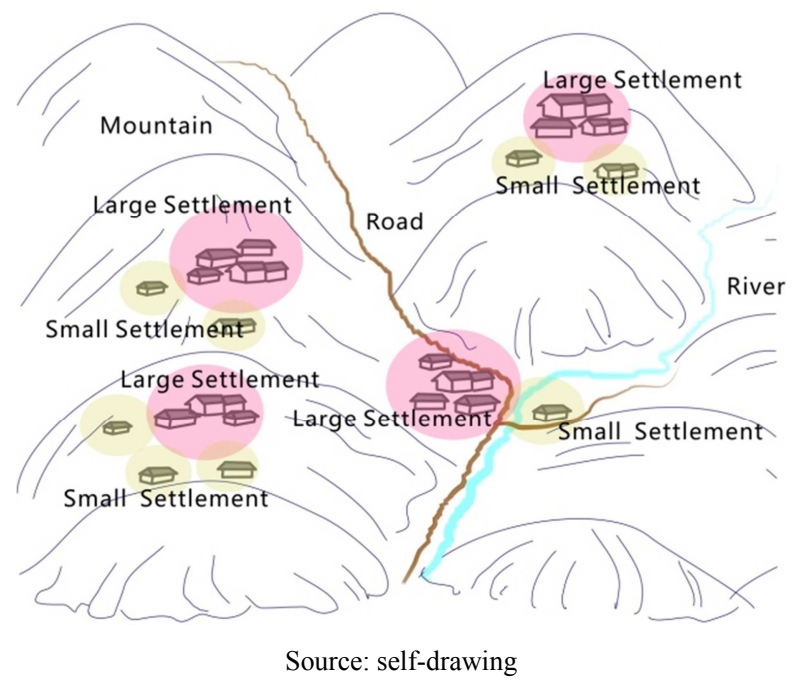

Figure 2. Relationship of ethnic settlement in the upper reaches.

\subsection{Military needs and Cultural Identity Construction of the Circle of Space Organization}

According to Li County Records (1997) [6], Toast management is strict to villagers, surname, Han, and chieftain separatism [7], leading to the upper reaches of the Minjiang River has long been in a war environment, causing the villagers in the settlements inter-family interdependence between the way to organize the space. The decentralized settlement and the small concentrated spatial organization of the settlement require the use of the terrain advantage of certain areas to build the towers [8,9]. (Figure 3) The towers and the topography of the mountains together encompass the security defense of certain geographical settlements and form the defense units of different geographical spaces. As the radiation range of towers increases with the increase of spatial distance, the defensive effect will diminish, and finally the formation of towers will lead to different social relations and cultural identities.

The external living environment and the military alliance needs the coupling, continue to strengthen the villagers' value recognition, and finally formed a social settlement structure and cultural space organizational structure between a certain geographical settlement, becoming a unique scenery of the upper reaches of the Minjiang River. Cultural value recognition strengthens the social connection among villagers and is a kind of geo-culture and military isomorphism based on the common interest goal.

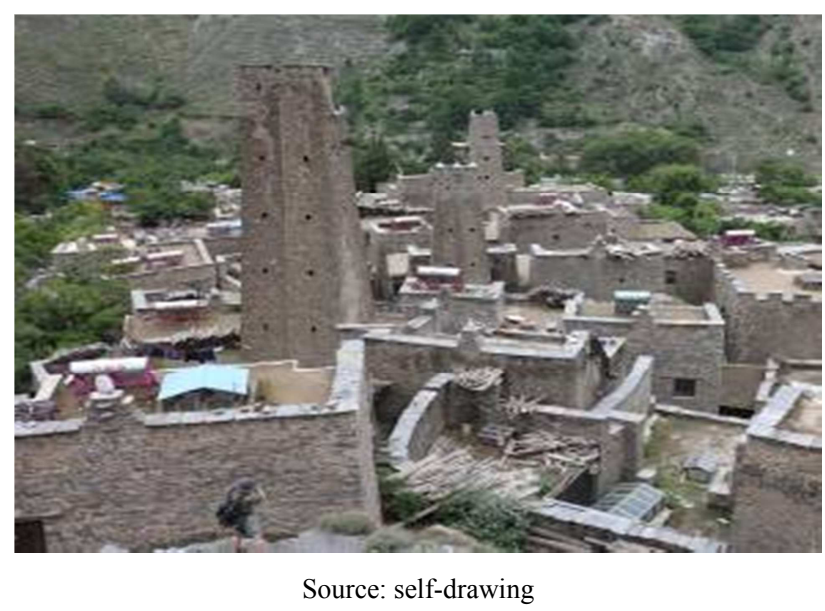

Figure 3. Taoping village in Li County, Sichuan Province.

\subsection{Villagers Lifestyle Multi-Choice Promoted Beaded Space Organization}

After the founding of the People's Republic, ethnic minorities carried out large-scale politicization of social organizations and, under the impetus of the government and market forces, these ethnic settlements experienced social and cultural changes [10]. Especially after the reform and opening up, the diversification of economic forms and the integration of different resources by the government have led to the development of the tourism industry and the opportunities for the villagers to go out for work. The economic capability and viability of villagers have been greatly enhanced. The interdependence between families and settlements has weakened, the defensive needs of space have been reduced, the intrinsic impetus for promoting the spatial organization structure of ethnic settlement has disappeared, and the internal space organization and settlement space with the organization of a discrete effect. (Figure 4) While accepting foreign culture, villagers can transform their spatial organization structure from blood and geopolitical to industrial relations through the way of self-chosen space construction.

Therefore, the spatial organization structure of ethnic settlement in the upper reaches of the Minjiang River can be summarized into three levels of characteristics: Firstly, the national culture of family space is characterized obviously; the boundaries of the inner space of settlement are vague and the whole organization of the settlement is strong; Social network relations and social structure. Secondly, in the light of external social instability, in order to ensure the safety of subsistence, the defensiveness of family space is combined with the defensiveness within and between settlements. There are some organized military or cultural alliances between settlements, among which tower represented. Thirdly, with the change in the mode of production of villagers and the improvement of their viability, the degree of dispersion in the settlement spatial organization structure gradually increased, 
and the internal space organization in the settlement showed a diversity of features. Settlement is a part of the tourism industry chain, which is only complementary to each other, and the social and cultural relations between spaces are weakened.

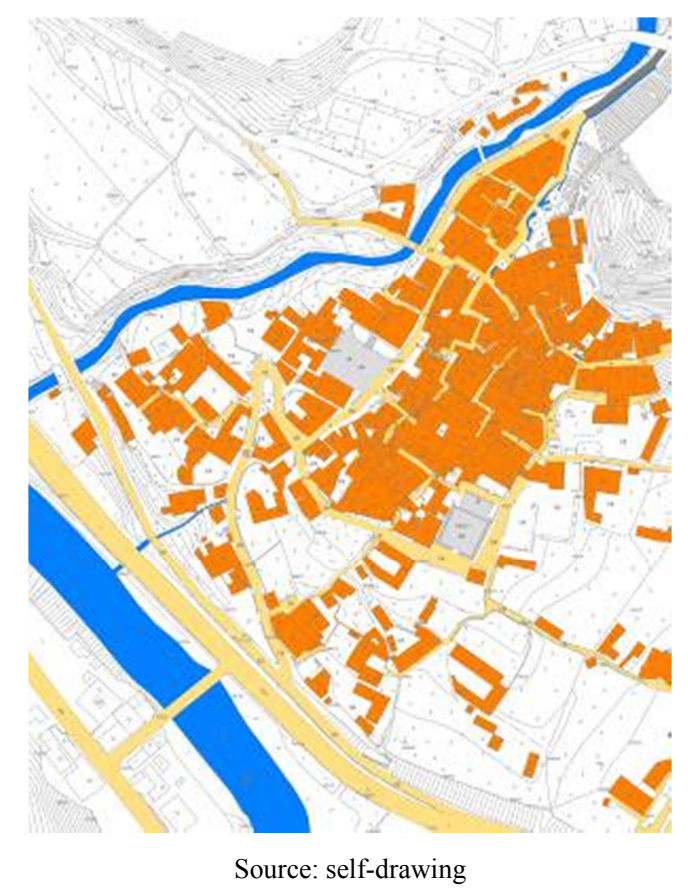

Figure 4. Taoping village in Li County, Sichuan Province.

\section{Strategy of Protecting the Spatial Structure of the Ethnic Settlements in the Upper Reaches of Minjiang River}

The characteristics of spatial organization structure of ethnic settlement have the following four characteristics: First, the villagers should adapt themselves to the objective material environment in which they live and reflect the spatial relations within the settlement. Second, the villagers should deal with the spatialization of the social and cultural attributes of the external social history and change, which is manifested in the spatial structure of the settlement. Third, the villagers' self-consumption of endogenous cultural and social attributes belongs to the self-organized construction mode with the same value of both the subject and the object. Fourth, the organizational structure of space is based on a high degree of identification of kinship and cultural values within settlements and is a manifestation of the consistency of social historical processes.

In view of the following characteristics of institutionalized rural settlement space construction: First, the changes in the external social environment for space construction are internalized as the expansion of living space for villagers and improvement of survival skills; second, institutionalized construction and self-organized society The process is different from that of creating units, it is difficult to transform the diversified needs of the family into the needs of the social subject; third, the different subjects of the implementation result in different values of the main subjects; fourth, the externalization of the traditional internal space practice is The creation of conditions for the orientation of values of different subjects has also created the conditions for dismemberment of the background conditions resulting from the special features of ethnic settlement. Therefore, the protection of national settlements in the upper reaches of the Minjiang River should start with the following aspects:

\subsection{Pay Attention to Social and Cultural Identification of Endogenous Ethnic Settlement in Institutionalized Space Practice}

The traditional settlements spatial organization relies on the high recognition of endogenous values of national beliefs and kinship and geo-relationship as the intrinsic link in the social practice of space practice. In the process of spatial practice, the traditional settlement spatial organization shows the values of settlements value community, cultural community, community of interests, community of destiny, society Community and other forms. Due to the involvement of power, the institutionalization of space practice has constructed the needs of a higher level of political and economic goals, at the same time as shaping the broader, higher-level social, economic and cultural development, has attracted more capital and main body into the practice of traditional settlement space, resulting in the construction of space practice villagers' social process and material space from long-term to short-term.

The height and breadth of this external subject construction exceeded the basic survival needs of the villagers, and used planning techniques to dismember the villager-led value-creating process and shaken the social stability and social structure of traditional society. Therefore, the organization of a single settlement space and the regional settlement space must be integrated in the overall material space construction process, in order to bring into play the special value of ethnic settlement.

\subsection{A Consistent Path of Constructing the Subject of Practice in Institutionalized Space and the Value Orientation of Endogenous Subjects}

The organization of settlement space is not only the result of coping with the external environment, but also the process of adapting its own living environment. The formation of these settlement space organizations is a long-term construction under the mode of self-organization. The main body of construction and the practical object are of the same height, which are the villagers' consumption of their own culture and social historical process.

In order to make the main body of institutionalized space consistent with the value of the main body of the settlement, it is necessary to practice and create a mechanism through social processes involving the villagers to become a part of the system of practice, in order to achieve the self-organization social process and space practice logical 
space practice fusion of traditional settlement.

\subsection{Realize the Long-Term Match between the Short-Term Timeliness of the Practice of Institutionalized Space and Villagers' Needs}

The ethnic settlements in the upper reaches of the Minjiang River, under the impetus of the government's administrative rights and industrialization technologies, completed the construction of material space, cultural representation and social space attributes within a short period of time, and also realized the large-scale spatial reconstruction of ethnic settlement in a certain area.

After the rural planning and construction have been institutionalized, the government has become an important way to guide the construction of the ethnic settlement space, which brings opportunities for the reconstruction of the ethnic settlement spatial organization [11-15]. Especially after the May 12 earthquake, the reconstruction of state funds, social subjects and market capital became the most extensive and largest spatial reconstruction in the history of ethnic settlement in the upper reaches of the Minjiang River. However, such a short period of material space construction neglected the established social relations and cultural identities for a long time, which caused many villagers to nostalgia for the past state of life and the harmonious foundation of social relations.

\section{Conclusion}

In view of the differences between the institutionalized practice of institutionalized practices and the traditional national settlement spatial organization, the study has the following enlightenments:

First of all, to avoid the impact of institutionalized space practices on the spatial culture of ethnic settlement, it is necessary to fully evaluate the historical and cultural values of the settlement space while creating a new cultural value of ethnic space.

Second, given the fate and cultural community attributes of villagers in terms of kinship, affinity and affinity, they make full use of these relationships in the practice of village planning in minority areas to design "collective houses of many generations (old people - children) of the characteristics of space, the villagers endogenous national space culture practice into institutionalized practice of identity.

Thirdly, through the "community building" which has the characteristics of national settlement, it is impelled to inspire the villagers' concern and enthusiasm for their own villages, change their passive protection into active protection, actively protect and update their protection so as to eventually achieve the goal of sustainable development of the village.

Finally, give full play to the role of administrative power, take advantage of the multi-latitude value of ethnic settlement, integrate the self-organizing settlement space and institutionalized space practice, and combine the driving force of the government with the appeal of villagers' needs. According to the characteristics of settlement space organization in different regional environment, different protection strategies and protection paths are constructed. Only in this way, the characteristics of national settlement can be inherited, beautiful rural construction can be achieved.

\section{Acknowledgements}

About the author: Meng Ying (1973-), female, Han nationality, Huaxian County, Henan Province, associate professor of urban and rural planning of Southwest University for Nationalities, research direction: urban and rural planning and design, theory, rural space culture and society, ethnic settlement sustainable development. Chengdu 610041, China;

This paper was supported by China National Scholarship Fund and National Social Science Fund Project "Research on the Protection and Inheritance of Sichuan Qiang Settlements Space Based on the Beliefs of National Belief" (16XMZ045).

\section{References}

[1] Mingqing La. Discussion on "developmental protection model" of national culture in post disaster reconstruction-Reflections on the protection of Qiang Nationality's culture after the earthquake. $[\mathrm{J}]$. Journal of Southwest University for Nationalities (Humanities and Social Sciences), 2010(12): 35-39

[2] Mingqing La. Discussion on "developmental protection model" of national culture in post disaster reconstruction-Reflections on the protection of Qiang Nationality's culture after the earthquake. [J]. Journal of Southwest University for Nationalities (Humanities and Social Sciences), 2010(12): 35-39

[3] Jun Xu. Re discussion on the subject position of national culture in post disaster reconstruction. [J]. ournal of Southwest University for Nationalities (Humanities and Social Sciences), 2010(12): 40-44

[4] Zhibin HU, Xingyuan He, Yuehui Li, Yuanman Hu. Distribution pattern and influencing factors of settlements in the upper reaches of Minjiang River. [J]. Journal of Liaoning Technical University, 2006(04): 623-625

[5] Zhaoping Yang, Yu Chang, Qingchun Wen. Spatial characteristics of cultivated land and residential land in arid valley of upper reaches of Minjiang River. [J]. Journal of Biology, 2007(03): 327-331

[6] Lixian Chronicles. Records of Lixian. [M]. Sichuan Nationalities Press, 1997

[7] Gang Mao. Ecological view-Settlements and buildings in high altitude mountainous areas of Southwest China. [M]. Nanjing: Southeast University press, 2003

[8] Xinjian Huang. Ethnic evolution and historical and cultural characteristics of the upper reaches of Minjiang River in the Tibetan Yi Corridor. [J]. Journal of Aba Teachers College, 2013(09): 20-23 
[9] Minqiu Shi, Qing Wang, Yalin Guo, Yu Zhang. Spatial distribution characteristics of settlements in the upper reaches of Minjiang River. [J]. Journal of Southwest University of Science and Technology, 2014(04): 33-37, 81

[10] Haijiang Wang. Impacts of Land Use in Alpine Settlement on the Boundary of the Dry Valley in the Upper Reaches of the Min River. [D]. Southwest University of Science and Technology. 2015

[11] The national Armageddon: Post quake reconstruction in Wenchuan (decision). [J]. Leadership decision information, 2008(26): 2-9

[12] The national Armageddon: Post quake reconstruction in Wenchuan (reconstruction). [J]. Leadership decision information, 2008(26):68-95
[13] The national Armageddon: Post quake reconstruction in Wenchuan (data). [J]. Leadership decision information, 2008(26): 36-45

[14] The national Armageddon: Post quake reconstruction in Wenchuan (support). [J]. Leadership decision information, 2008(26): 22-35

[15] The national Armageddon: Post quake reconstruction in Wenchuan (Reflect). [J]. Leadership decision information, 2008(26): 62-67. 